\title{
Prevalence of Verbal Abuse Among Doctors in Tertiary Care Hospital
}

\author{
Kalpana Silwal, ${ }^{1}$ Sarala Joshi \\ 'Department of Nursing, Chitwan Medical College and Teaching Hospital, Bharatpur, Chitwan, Nepal, ${ }^{2} \mathrm{Om}$ Health Institute, \\ Nursing College, Kathmandu, Nepal.

Introduction: Verbal abuse is the act of forcefully criticizing, insulting or denouncing another person. Verbal abuse can be devastating to doctors and may cause long lasting emotional and psychological damage. This study aims to find the prevalence of verbal abuse among doctors in tertiary care hospital.

Methods: This descriptive cross-sectional study was conducted among doctors in a tertiary care hospitals, Chitwan from January to July, 2019 after taking ethical approval. Convenience sampling was done. Self administered questionnaire was distributed and data was collected. Point estimate at $95 \%$ CI was done for binary data along with frequency and proportion. Data were entered and calculations were done in Microsoft excel.

Results: Verbal abuse was found among 80 (33.3\%) respondents at 95\% Confidence Interval (27.51$39.09 \%)$ and most $51(63.8 \%)$ of perpetrators were relatives of the patients. Most $38(47.5 \%)$ of the doctors were often worried in workplace. Incident of the verbal abuse was more $35(43.6 \%)$ in morning and least $14(17.4 \%)$ in night. Most $22(27.5 \%)$ of the doctors did not take any action for incident although most $42(52.5 \%)$ of the doctors were encouraged by colleagues to take action.

Conclusions: Prevalence of verbral abuse among the doctors were found out to be similar as the previous studies conducted in similar settings. This study has shown that doctors were frequently verbal abused by patient's relatives and were abused mostly in morning shift and were often worried in workplace.

Keywords: abuse; doctors; workplace.

\section{INTRODUCTION}

Verbal abuse has been known as a significant issue Verbal abuse against doctors can affect the work performance and productivity in hospital. ${ }^{1}$

The prevalence of workplace violence in the last 12 months was found to be $63.41 \%$, whereas the lifetime prevalence was found to be $78.05 \% .^{2}$ Violence against doctors is increasing in Nepal and will continue to surge until the effective measures to improve healthcare in our country. ${ }^{3}$ However, this issue is under researched and little evidence exists so the researcher interest to do study on this research problem.
Maximum (87.3\%) of the reported cases were of verbal violence while $8.6 \%$ of the cases were of physical violence. ${ }^{4}$ Higher rates of burnout, low self-esteem and self-destructive aggression are main symptoms in health care professions. ${ }^{5}$

The present study aims to find the prevalence of verbal abuse among doctors in a tertiary care hospital.

Correspondence: Mrs. Kalpana Silwal, Chitwan Medical College and Teaching Hospital, Bharatpur, Chitwan, Nepal. Email: kalpanasilwal@gmail.com, Phone: +977-9841516491. 


\section{METHODS}

This descriptive cross-sectional study was conducted in two tertiary care hospitals: Bharatpur hospital and Chitwan Medical College and Teaching Hospital, over a period of January to July 2019. Ethical approval was taken from Ethical Review Board of National Health Research Council and also from Chitwan Medical College and Teaching Hospital and Bharatpur Hospital.

During the study 276 questionnaires were distributed, 255 were returned and 15 were discarded due to incomplete information for the study.

Convenience sampling was done and sample size was calculated using the formula:

$$
\begin{aligned}
\mathrm{n} & =\mathrm{Z}^{2} \times(\mathrm{p} \times \mathrm{q}) / \mathrm{e}^{2} \\
& =1.96^{2} \times 0.3 \times(1-0.3) / 0.06^{2} \\
& =224
\end{aligned}
$$

where,

$\mathrm{n}=$ required sample size

$\mathrm{p}=$ prevalence the burden of verbal abuse among doctors (30\%, educated guess)

$q=1-p$

$\mathrm{e}=$ margin of error, $6 \%$

$\mathrm{Z}=1.96$ at $95 \% \mathrm{Cl}$

The total sample size calculated was 224 and after adding non-response rate as $7 \%$, the total sample size taken was 240 . The data was collected in a selfadministered questionnaire and analyzed by Statistical Package for Social Sciences 20 version. Point estimate at $95 \% \mathrm{CI}$ was done for binary data along with frequency and proportion.

\section{RESULTS}

Out of 240 study participants, verbal abuse was found in 80 (33.3\%) participants at $95 \% \mathrm{Cl}$ (27.51-39.09) (Table 1). Thirty eight (47.5\%) were found to be often worried and 5 (6.3\%) were never worried. Out of total, $42(52.5 \%)$ respondents were encouraged by colleague to take actions for the verbal abuse but 22 (27.5\%) respondents did not take any actions (Table 1).

\begin{tabular}{|l|}
\hline \multicolumn{1}{|c|}{ Table 1 . Distribution of Verbally abused in workplace. } \\
\hline \multicolumn{1}{|c|}{ Statement } \\
\hline $\begin{array}{l}\text { Verbally abused (Yes) } \\
\text { Statement }\end{array}$ \\
$\begin{array}{l}\text { verbally abused in the last } 12 \text { months } \\
(\mathrm{n}=80)\end{array}$
\end{tabular}

\begin{tabular}{|cc|} 
always worried & $20(25)$ \\
often worried & 38 \\
sometimes worried & $(47.5)$ \\
seldom worried & $9(11.2)$ \\
Never worried & $8(10)$ \\
\hline
\end{tabular}

Majority 170 (70.8\%) of the respondents were verbally abused for 6-12 months and $1(0.4 \%)$ of the respondents were verbally abused for 37- 48 months (Table 2). Out

\begin{tabular}{|c|c|}
\hline \multicolumn{2}{|c|}{$\begin{array}{l}\text { Table 2. Respondents' work experience and time of } \\
\text { Incident of verbal abuse. }\end{array}$} \\
\hline Time of verbral abuse $(n=80)$ & n (\%) \\
\hline Morning & 35 (43.5) \\
\hline Evening & $31(39.0)$ \\
\hline Night & $14(17.5)$ \\
\hline
\end{tabular}
of total abused, 35 (43.6\%) faced verbral abuse on morning time followed by evening and night.

Perpetrators in the last 12 months, majority 51 (63.8\%) perpetrators were relatives of the client or patient (Table

\begin{tabular}{|c|c|}
\hline \multicolumn{2}{|c|}{$\begin{array}{l}\text { Table 3. Distribution of perpetrators in the last } 12 \\
\text { months. }\end{array}$} \\
\hline $\begin{array}{l}\text { Perpetrators of the verbal } \\
\text { abuse }(n=80)\end{array}$ & n (\%) \\
\hline patient/client & $15(18.8)$ \\
\hline relatives of the patient/ client & $51(63.8)$ \\
\hline management / supervisor & $14(17.5)$ \\
\hline
\end{tabular}
3). Least $14(17.5 \%)$ perpetrator were supervisors or managers.

Sociodemographic characteristics of the participants is shown The mean age of the participants was $27.82 \pm 4.52$ years and 215 (89.5\%) were the age of 21-25 years. Majority of the participants; 153 (63.7\%) were not married and 213 (88.8\%) were full time workers (Table 4).

\begin{tabular}{|ll|}
\hline $\begin{array}{l}\text { Table 4. Respondents' socio- demographic } \\
\text { characteristics. }\end{array}$ \\
\hline Age of respondents (years) & $\mathrm{n}(\%)$ \\
$21-25$ & $215(89.5)$ \\
$26-30$ & $22(9.2)$ \\
$31-35$ & $3(1.3)$ \\
Total & $240(100)$ \\
\hline
\end{tabular}

\section{DISCUSSION}

In our study, verbal abuse was found among 80 (33.3 $\%)$ respondents. A study conducted in New Delhi, India had found that verbal violence was the most common type of violence, $62(87.3 \%) .^{4}$ According to the data 
of the Bureau of Labour Statistics (BLS), USA reported that prevalence of workplace violence among physicians to be $56 \%-75 \%{ }^{6}$ in 2014 in Manipur found that $78 \%$ of doctors had experienced some form of violence. ${ }^{7}$ Our study has shown that most of perpetrators 51 (63.8\%) were relatives of the patients. Study in India also showed the similar finding i.e. patients and their relatives are the most common perpetrators. ${ }^{6}$ Other study also reported that in most of the cases of violence, the perpetrators were either patients or their relatives. Either patients or their attendants were the main perpetrators of violence which was $84.5 \%{ }^{4}$ Our study showed that the incidence of the verbal abuse was more $35(43.6 \%)$ in morning and least 14 $(17.4 \%)$ in night. Similar finding was by a study which showed that maximum events of the verbal abuse took place in morning than evening and least night shifts. ${ }^{4}$ Another study found that verbal abuse incidence occurred especially in evening and night time which is contradict of this study. ${ }^{7}$ In this study, we found out that most $38(47.5 \%)$ of the respondents were often worried in workplace. One of the study reported that the increasing incidences of violence against doctors in their workplaces is the important reason for stress among these healthcare workers. Maximum (87.3\%) of the reported cases were of verbal violence. ${ }^{4}$ Other study also showed that higher rates of burnout, low self-esteem and self-destructive aggression are among the violence in the health care system. ${ }^{5}$

A study concluded that verbal abuse obviously impact on the effectiveness of health systems, especially in developing countries which should minimize and should prevented as much as possible. ${ }^{6}$ Other study had suggested that organizations must adopt zero-tolerance policies and training and in-service education should be given to prevent incidence of the verbal abuse.?

\section{CONCLUSIONS}

Prevalence of verbral abuse among the doctors were found out to be similar as the previous studies conducted in similar settings. This study has shown that doctors were frequently verbal abused by patient's relatives and were abused mostly in morning shift and were often worried in workplace. Furthermore, for the nation's parlous state of healthcare to improve, much emphasis should be placed on ensuring to prevent abuse in the workplace. So necessary that certain strategies are plan to guarantee the safety of health care providers in every health care institutions in Nepal.

\section{ACKNOWLEDGEMENTS}

I heartily acknowledge to the help of Ms. Taniya Thapa and Ms. Alisha Joshi, Lecturers of Chitwan Medical College And Teaching Hospital, School of Nursing. I also express gratitude to my friend Associate Professor, Tumla Shrestha (PhD Schloar) Maharajgunj Nursing Campus, all the respondents who participated in the study and all the people who helped me during my data collection period.

Conflict of Interest: None.

\section{REFERENCES}

1. Subedi S, Hamal M, Kaphle HP. Sexual harassment in the hospital: are nurses safe. International Journal of Health Sciences and Research. 2013;3(6):41-7. [Full Text]

2. Pund SB, Kuril BM, Doibale MK, Ankushe RT, Kumar P, Siddiqui N. Study of workplace violence, its risk factors and perceptions about workplace security in doctors of Paithan. Int J Community Med Public Health. 2017 May 22;4(6):1987-92. [ubMed | Full $\underline{\text { Text }} \mid \underline{\text { DOI] }}$

3. Magar A. Violence against doctors in Nepal. J Nepal Med Assoc. 2013 Oct 1;52(192):I-I. [ [PubMed | Full Text]

4. Kumar M, Verma M, Das T, Pardeshi G, Kishore J, Padmanandan A. A study of workplace violence experienced by doctors and associated risk factors in a tertiary care hospital of South Delhi,
India. J Clin Diagn Res. 2016 Nov;10(11):LC06. [라Med | Full $\underline{\text { Text }} \mid \underline{\mathrm{DOI}}]$

5. Coursey JH, Rodriguez RE, Dieckmann LS, Austin PN. Successful implementation of policies addressing lateral violence. AORN J. 2013 Jan 1;97(1):101-9. [PubMed | DOI]

6. Anand T, Grover S, Kumar R, Kumar M, Ingle GK. Workplace violence against resident doctors in a tertiary care hospital in Delhi. Natl Med J India. 2016 Nov-Dec;29(6):344-8. [P PubMed | Full Text]

7. Sofield L, Salmond SW. Workplace violence. A focus on verbal abuse and intent to leave the organization. Orthop Nurs. 2003 Jul-Aug;22(4):274-83. [ubMed | DOI] 